\title{
Challenges of Reaching Consensus on Assessing Which Non-native Plants Are Invasive in Natural Areas
}

\author{
Alison M. Fox ${ }^{1}$, Doria R. Gordon, and Randall K. Stocker \\ Department of Agronomy, Department of Botany, and Center for Aquatic and Invasive Plants, University of \\ Florida, Gainesville, FL 32611
}

Reaching consensus on which naturalized non-native species are invasive is important for several reasons. Agreement is necessary for widespread compliance and participation in efforts to stop further dispersal, and for obtaining assistance in and support for early detection and control programs. Mechanisms for predicting which species might become invasive after introduction may be expected to be somewhat open to debate, but, surely, it cannot be very difficult to agree on the invasiveness of species that are already here.

When economic impacts on commodity groups are the primary concern (e.g., agricultural weeds) such agreement is usually attained easily. However, for species that have primarily ecological impacts the situation is much less straightforward. The problem typically revolves around attempts to distinguish between "Invasive" and "Non-invasive" characteristics and impacts. Non-native species can have a continuum of ecological impacts in natural ecosystems, ranging from a relatively harmless, sporadic appearance of a species confined to disturbed areas, to total replacement and disruption of indigenous communities. Selection of a dividing point along this continuum of impacts is difficult because plants may shift their relative position with time, either becoming more disruptive as populations increase, or being less disruptive as native or introduced herbivores and pathogens take their toll. Superimposed on this dynamic range are the myriad values and experiences that influence people's perceptions of what level of ecological disruption is acceptable. This spectrum ranges from the view that natural ecosystems should be protected from any non-native incursions (e.g., where a single plant is potentially displacing a native plant), to the view that nothing short of native species extinction is worthy of concern.

Fortunately, people can agree about the ecological impacts of many naturalized, nonnative plant species because either their severe ecological disruption is well recognized, such as cheatgrass (Bromus tectorum L.), melaleuca [Melaleuca quinquenervia (Cav.) Blake], and hydrilla (Hydrilla verticillata (L.F.) Royle), or they are just opportunistic weeds of highly

\footnotetext{
Received for publication 2 May 2002. Accepted for publication 7 May 2002. The contributions of Hillary Cherry, Eli Jimenez, Joan Dusky, and Linda Tyson, and the support of the Univ. of Florida's Invasive Plants Working Group are much appreciated. This research was supported by a grant from the Florida Nurserymen and Growers Association, and the Florida Agricultural Experiment Station, approved for publication as Journal Series No. R-08546.

${ }^{1}$ To whom reprint requests should be addressed. E-mail address: amfox@mail.ifas.ufl.edu
}

disturbed lands that pose little threat to natural ecosystems. Controversy haunts the middle ground, especially when the species are in an early stage of their invasion and/or have high economic value. In such situations, consensus is most likely to be achieved if there is a clear and scientifically based set of criteria on which logical decisions about the status of invasive species can be based.

\section{DEFINING INVASIVENESS IN FLORIDA}

Florida is certainly not a typical state when it comes to problems arising from invasive species. The state spent over $\$ 90$ million for control or management of all types of invasive species in 1999/2000, and has $\$ 25$ million and $\$ 6$ million budgeted for aquatic and upland non-native plant management, respectively, by the Dept. of Environmental Protection alone in 2001/2002. However, many of the controversial issues are the same as elsewhere. Similar to Hawaii and California, if Florida gets to experience and try to resolve some of these issues earlier than other states, perhaps some useful lessons can be passed along.

Invasive plants are regulated under two state rules in Florida. The Dept. of Environmental Protection Rule 62C-52 was implemented in 1986 to regulate the movement and possession of nuisance aquatic and wetland plants (Florida Dept. of Environmental Protection, 2001). In 1993, the Florida Dept. of Agriculture and Consumer Services Rule 5B-57 established regulation of the introduction or release of noxious weeds (Florida Dept. of Agriculture and Consumer Services, 2001). Initially, this list of plants was based on the Federal Noxious Weed List administered by the U.S. Dept. of Agriculture and hence, included mostly agricultural pests (U.S. Dept. of Agriculture, 2001). Subsequently, several plants that primarily impact natural areas have been added, including two that were widely sold for landscaping in Florida, Chinese tallow tree [Sapium sebiferum (L.) Roxb.] and carrotwood [Cupaniopsis anacardioides (A.Rich.) Redkf]. In consultation with the ornamental horticulture industry, these species were phased-out of production and sale over a 2-year period, once the ecological impacts of well-established infestations were evident.

In addition to these statutory lists of prohibited species, the Florida Exotic Pest Plant Council (FLEPPC), a professional society of resource-managers and researchers established in 1984, has been publishing lists of invasive plant species since 1991 (Florida Exotic Pest Plant Council, 2001). A "List Committee" of about 12 members revises biennially the lists based principally on plant distributional information and reports of ecological impacts in Florida. The Category I list includes "invasive exotics that are altering native plant communities by displacing native species, changing community structure or ecological functions, or hybridizing with native species. This definition does not rely on the economic severity or geographic range of the problem, but on the documented ecological damage caused" (quoted from Florida Exotic Pest Plant Council, 2001). On the 2001 lists, there are 68 species in Category I and 56 species in Category II. This latter category includes species "that have increased in abundance or frequency but have not yet altered Florida plant communities to the extent shown by Category I species" (quoted from Florida Exotic Pest Plant Council, 2001). There are several stated purposes for these lists (Florida Exotic Pest Plant Council, 2001), but these all focus with a precautionary intent on being a mechanism to alert managers of natural areas to current or potential problem species.

A high proportion of the Category I species are known (47\%), or are thought (an additional $22 \%$ ), to have been introduced for ornamental purposes; $21 \%$ were brought in for agricultural use; and only $6 \%$ are thought to be accidental introductions (information updated from Gordon and Thomas, 1997). Of the 44 Category I species that are not prohibited by law, 24 were still for sale in 1999.

Problems started to arise when cities or counties that wanted to be particularly proactive on issues related to invasive plants decided to enact local ordinances that went beyond the state rules. Looking for guidance on which species were most problematic in their areas, city and county commissions frequently turned to the FLEPPC lists and used them as a basis for restricting the local use of particular plants. By 2000, 17 counties and 4 cities had ordinances restricting a total of 36 species, 17 of which were not prohibited by state rules. These actions quickly got the attention of members of the ornamental horticulture and landscaping industries. The industry wanted clarification of the criteria that had been used to place species on the FLEPPC lists, in order to understand the criteria that might determine whether a species was being locally regulated.

The FLEPPC does not use or publish a list of such criteria but relies upon the expert opinions of specialists in botany and natural areas management. Consolidated descriptions and information on the ecological impacts of most of the Category I species are now available (Langeland and Craddock Burks, 1998). However, concerns remain that no one outside the FLEPPC List Committee understands exactly why one species was placed on a particular list 
while another species was not. Additionally, no one could review or question the documentation or decision-making process used because none of those aspects of list development was recorded.

In an effort to resolve some of these conflicts of interest and opinion, representatives of the FLEPPC began meeting with officers of the Florida Nurserymen and Growers Association (FNGA) and the Tampa Bay Wholesale Growers (TBWG). In 1999, these latter organizations recommended that Florida's nursery and landscape industry professionals voluntarily cease the propagation, sale, and use of 11 Category I species, such as sword fern [Nephrolepis cordifolia (L.) Presl] and guava (Psidium guajava L.). Continuing this effort in 2001, an additional 34 Category II species (nine of which have commercial value) were recommended for discontinued use in Florida by the FNGA and TBWG. While further discussions about other species continue, this leaves 13 FLEPPC Category I species that are still on the market in Florida, some of which are popular landscape plants, for example, asparagus fern [Asparagus densiflorus (Kunth) Jessop], lantana (Lantana camara L.), Japanese honeysuckle (Lonicera japonica Thunb.), and heavenly bamboo (Nandina domestica Thunb.).

\section{IFAS ASSESSMENT OF NON-NATIVE PLANTS IN FLORIDA'S NATURAL AREAS}

Extension agents and specialists from the Univ. of Florida's Institute of Food and Agricultural Sciences (IFAS) became involved in these discussions when asked to provide expert opinions about the invasiveness of certain plant species to city and county commissions. Some faculty recommended certain non-native species for landscaping, while others supported adoption of the FLEPPC lists and were developing control programs for the same species. In an effort to resolve these internal conflicts, the IFAS Invasive Plants Working Group, which has representatives from departments such as Agronomy, Botany, Environmental Horticulture, and Wildlife Ecology and Conservation, established a subcommittee in early 1999 to develop a tool for assessing non-native plants in Florida's natural areas (hereafter called the "IFAS Assessment").

The primary purpose of the IFAS Assessment was to provide a mechanism to be used within the Univ. of Florida to develop consistent descriptions of, and recommendations for, the use and management of non-native plants in Florida. In addition to determining whether a species was invasive, this assessment included criteria for other issues, such as management difficulty and commercial value. Incorporation of these two issues results in a broader, less precautionary evaluation of non-native plants than that of the FLEPPC lists, reflecting the different objectives of the two processes. Economic criteria do not negate or lessen the significance of any ecological impacts of a species, but may result in a recommendation for a more formal risk-benefit analysis. Such analyses are typically performed in the develop- ment of state regulations prohibiting the use of a species. Asecondary purpose of the assessment was to identify the frequent data-gaps in our knowledge of these species that would assist in setting research priorities.

The requirements for the IFAS Assessment were clear: it would have precisely defined criteria that are defendable by all IFAS faculty, and all evidence and decisions would be documented and archived for anyone to review. Far less is published about most invasive species than desired for an assessment, and anecdotal information can be difficult to defend without further substantiation. Thus, documentary evidence was defined as being either published and quantitative, or as written observations from three relevant experts (e.g., professional botanists and land managers), all of whom must be willing and able to confirm their observations.

After reviewing similar assessments that have been developed elsewhere (e.g., Hiebert and Stubbendieck, 1993) it was decided to limit the IFAS Assessment, as much as possible, to non-predictive information about existing plant populations in Florida. Thus, the IFAS Assessment is intended to describe the status of a species in Florida at the time of evaluation. It was feared that the uncertainty inherent in predictive criteria would jeopardize the credibility of the whole assessment. However, there is agreement among members of the IFAS Invasive Plants Working Group and representatives of the horticulture industry in Florida that predictive evaluations are certainly needed for this state, both for species not yet introduced and for those recently arrived but for which ecological information is lacking.

Other differences from existing assessments and greater details about the format of the IFAS Assessment have been provided by Fox et al. (2000). The IFAS Assessment is available to download from Fox et al. (2001). The assessment has five major sections, the first of which broadly defines invasiveness as the establishment of self-sustaining plant populations that are expanding within a natural plant community with which they had not previously been associated (Vitousek et al., 1995). To be declared as being invasive a plant must be documented in natural areas where there has not been significant human disturbance or it must have survived restoration of the natural communities. Because of the significant environmental variation across the state, which covers $6.5^{\circ}$ latitude spanning subtropical to temperate conditions, the assessment of invasiveness and ecological impacts of a species is done separately for each of three climatic zones in Florida (northern, central, and southern)

The IFAS Assessment uses four indices, each of which has a series of yes/no questions and from which is derived a status category. The indices are Ecological Impacts (Low, Medium, High and Very High categories), Potential for Expansion, Management Difficulty, and Commercial Value (all with either Low or High categories). Based on the permutation of these index categories, one of the following five conclusions is assigned to each climatic zone for a species: Not considered a problem invasive at this time; caution, prevent escape of this plant; avoid use of this plant and either reassess in two years, or proceed with formal risk-benefit analysis; only specified and limited use that prevents escape; or do not use this plant.

The IFAS Assessment is intended to provide consistent guidance to IFAS Extension personnel in making recommendations for use of these plants. It has no regulatory authority and is obviously superseded by any state or federal prohibitions. Prohibited species are immediately identified with a "Do not use this plant" conclusion at the beginning of the assessment. The assessment requires that all species be reassessed on a regular basis and if pertinent information becomes available (especially in relation to new infestation sites or impacts). Similarly, cultivars that differ in significant aspects, such as sterility, should be assessed separately.

This assessment was reviewed both within IFAS and by a number of external reviewers, including representatives of FNGA and TBWG. It was approved for use in June 2000. At that time, 20 species were chosen, many from the FLEPPC Category I list, for the first formal application of the IFAS Assessment. The results for those first 20 species were tentatively released a year later, pending final approval from the Invasive Plants Working Group of revisions to the assessment. It cost over $\$ 10,000$ to collect and compile the data for those 20 species.

Two species, carrotwood [Cupaniopsis anacardiodies (A. Rich.) Redkf.] and field mustard (Brassica campestris L.) that would not normally be run through the assessment, had the expected results, "Do not use" and "Not considered a problem invasive at this time," respectively. Carrotwood is listed as a prohibited plant in Florida and field mustard has not been reported in undisturbed natural areas. As a result of the specified criteria and documentary requirements, the FLEPPC Category I listed species, asparagus fern only received a "Caution" conclusion for all three geographic zones. Only 4 of the first 20 species assessed currently occur in all three zones, and 12 species were assigned different conclusions for different zones. For example, guava had "Avoid with risk-benefit analysis" in the south, "Caution" in the central zone, and "Not considered a problem invasive at this time" for the north where it is considered unlikely to survive.

Two FLEPPC Category I species of great interest in the landscaping and ornamental horticulture industries, Chinese privet (Ligustrum sinense Lour.) and heavenly bamboo, had "Do not use" conclusions for their north and central zones, but were assigned "Caution" in the south where neither currently occur. Conversely, wax begonia (Begonia cucullata Willd.; Category II) and lantana (Category I) were assigned "Caution" in the north (where they both occur) but lantana received "Do not use" and begonia received "Avoid with risk-benefit analysis" in the central and south zones. These conclusions were assessed for the "wild-type" species that may no longer be used in the horticulture in- 
dustry. Sterile cultivars that are on the market for both of these species would need to be assessed independently and would likely receive more favorable conclusions. Begonia, in the south and central zones, was also eligible for a conclusion of "only specified and limited use that prevents escape." Specified uses, such as being limited to indoor foliage, could be defined by the Invasive Plants Working Group if they considered that, with careful disposal requirements, the escape of this species into natural areas could be prevented.

\section{FUTURE PROGRESS WITH THE IFAS ASSESSMENT}

Experience gained from the assessment of these first 20 species has been valuable in revising and streamlining both the IFAS Assessment and the methods used to gather data. In the future, greater use will be made of the Internet, both for soliciting relevant information and for posting partial and complete results. The IFAS Assessment is a more complex document than originally envisioned, and it is also likely to continue to evolve as more species are tested and more information sources become available. Based on our experience so far, we have concluded that personnel conducting the IFAS Assessment need to be dedicated to datagathering and completion of the assessment. The status of some species will change over time and hence will require regular reviews of distributional databases, and reevaluation through the assessment. This part of the process is easier if concentrated in one academic unit, however, all results are presented to the interdisciplinary Invasive Plants Working Group for final review before publication. Ultimately, the development of an interactive web-based version would greatly simplify the process.

While many of the species discussed here may seem to be only of relevance to Florida and Hawaii, there is no reason why, with appropriate adjustments for geographical zones, the assessment itself could not be applied in other states or regions. Groups in Ohio and Indiana have already expressed interest in adapting sections for their local use and we would be pleased to learn of other applications. Efforts are also being made at the national level to develop criteria for ranking the invasiveness of non-native plants. Species would still need to be evaluated on a regional basis to account for variations in their establishment and impacts in different climates and habitats. However, selection of the best approaches from the available regional assessments could result in a comprehensive instrument that would provide consistency to evaluations of non-native plants in natural areas throughout the nation.

\section{Literature Cited}

Florida Department of Agriculture and Consumer Services. 2001. Rules of the Department of Agriculture and Consumer Services, Division of Plant Industry Chapter 5B-57. Cited from the World Wide Web, 31 Dec. 2001. http: //doacs.state.fl.us/ pi/5b-57.htm.

Florida Department of Environmental Protection. 2001. Rule 62C-52.011 Prohibited Aquatic
Plants. Cited from the World Wide Web, 31 Dec. 2001.http://www.dep.state.fl.us/lands/invaspec/ 2ndlevpgs/perrules.htm\#62C-52.011.

Florida Exotic Pest Plant Council. 2001. List of Invasive Species. Cited from the World Wide Web, 31 Dec. 2001. http://www.fleppc.org/01list.htm.

Fox, A.M., D.R. Gordon, J.A. Dusky, L.L. Tyson, and R.K. Stocker. 2000. The story behind the IFAS assessment of non-native plants in Florida's natural areas. Cited from the World Wide Web, 31 Dec. 2001. http://edis.ifas.ufl.edu/AG100.

Fox, A.M., D.R. Gordon, J.A. Dusky, L.L. Tyson, and R.K. Stocker. 2001. IFAS assessment of non-native plants in Florida's natural areas. Cited from the World Wide Web, 31 Dec. 2001. http://agronomy.ifas.ufl.edu/ IFASAssessment2001.pdf.

Gordon, D.R. and K.P. Thomas. 1997. Florida's invasion by nonindigenous plants: History, screening, and regulation, p. 21-37. In: D Simberloff, D.C. Schmitz, and T.C. Brown (eds.). Strangers in paradise. Island Press, Washington, D.C.

Hiebert, R.D. and J. Stubbendieck. 1993. Handbook for ranking exotic plants for management and control. U.S. Dept. of Interior Natural Resources Report NPS/NRMWRO/NRR-93/08.

Langeland, K.A. and K. Craddock Burks. 1998 Identification and biology of non-native plants in Florida's natural areas. Univ. of Florida Publications, Gainesville.

U.S. Department of Agriculture. 2001. Federal noxious weed list. Cited from the World Wide Web, 31 Dec. 2001.http://www.aphis.usda.gov/ ppq/permits/fnwsbycat-e.PDF.

Vitousek, P., L. Loope, C. D'Antonio, and S.J. Hassol. 1995. Biological invasions as global change, p. 213-336. In: S.J. Hassol and J. Katzenberger (eds.). Elements of change 1994. Aspen Global Change Inst., Aspen, Colo. 